\title{
Resistance Training and Protein Supplementation Increase Strength After Bariatric Surgery: A Randomized Controlled Trial
}

\author{
Jean-Michel Oppert (iD 1*, Alice Bellicha ${ }^{1,2}$, Celina Roda ${ }^{3,4,5}$, Jean-Luc Bouillot ${ }^{6}$, Adriana Torcivia ${ }^{7}$, Karine Clement ${ }^{1,8}$, \\ Christine Poitou ${ }^{1,8}$, and Cecile Ciangural
}

Objective: Physical activity and dietary regimens to optimize health outcomes after bariatric surgery are not well known. This study aimed to determine whether resistance training with dietary protein supplementation is effective in maintaining body composition and physical fitness after obesity surgery.

Methods: Seventy-six women with obesity undergoing Roux-en-Y gastric bypass were randomly assigned at the time of surgery to receive either usual care (controls [CON], $n=22$ ), usual care and additional (whey) protein intake (PRO, $n=31$ ), or usual care, additional protein intake, and supervised strength training for 18 weeks (PRO+EX, $n=23)$. The primary outcome was pre- to 6 -month postsurgery change in lean body mass (by dual-energy $\mathrm{x}$-ray absorptiometry). Secondary outcomes included changes in muscle strength (by onerepetition maximum testing).

Results: Loss over time in lean body mass did not differ between groups (CON: mean,-8.8 kg; 95\% Cl: -10.1 to $-7.5 \mathrm{~kg}$; PRO: mean, $-8.2 \mathrm{~kg}$; $95 \% \mathrm{Cl}:-9.3$ to $-7.1 \mathrm{~kg}$; PRO+EX: mean, $-7.7 \mathrm{~kg} ; 95 \% \mathrm{Cl}:-9.0$ to -6.5 $\mathrm{kg} ; P=0.899)$. The increase in relative lower-limb muscle strength was higher in the PRO+EX group (+0.6 [0.3 to 0.8$]$ ) versus +0.1 ( -0.1 to 0.4 ) and $+0.2(0.0$ to 0.4$) \mathrm{kg} / \mathrm{kg}$ body mass in CON and PRO groups, respectively $(P=0.021)$.

Conclusions: Loss in muscle strength observed after bariatric surgery can be overcome by resistance training with additional protein intake.

\section{Introduction}

In patients with severe obesity, bariatric surgery results in marked and sustained weight loss, decreased mortality (1), and improvement in obesity comorbidities, physical function, and health-related quality of life $(2,3)$. To enhance health benefits, lifestyle changes represent a major component of follow-up after bariatric surgery $(2,3)$. Physical activity is a cornerstone of obesity treatment in general (4); however, in patients undergoing bariatric surgery, little is known about the effects of physical activity on health outcomes, including body composition and physical fitness (5). Randomized controlled trials (RCTs) that have assessed the effects of an exercise training program in the first year after bariatric surgery are few (6-9). Findings from a narrative review (5) suggested improvements in metabolic health and cardiorespiratory fitness after endurance training, although there was no consistent additional effect on surgery-induced loss in fat mass and lean body mass.

Resistance or strength training is known to increase lean body mass and muscle strength (10). Muscle strength is an important marker related to functional capacity, cardiovascular disease risk factors, and mortality (11-13). Patients undergoing bariatric surgery, such as Roux-en-Y gastric bypass (RYGB), experience a substantial decrease in lean body

\footnotetext{
${ }^{1}$ Department of Nutrition, Pitié-Salpêtrière Hospital, Assistance Publique-Hôpitaux de Paris (AP-HP), Sorbonne Université, Institute of Cardiometabolism and Nutrition (ICAN), Paris, France. Correspondence: Jean-Michel Oppert (jean-michel.oppert@aphp.fr) ${ }^{2}$ Laboratory of Bioengineering, Tissues and Neuroplasticity (BIOTN), University Paris-Est, Créteil, France ${ }^{3}$ ISGlobal, The Barcelona Institute for Global Health, Barcelona, Spain ${ }^{4}$ Universitat Pompeu Fabra (UPF), Barcelona, Spain ${ }^{5}$ CIBER Epidemiología y Salud Pública (CIBERESP), Barcelona, Spain ${ }^{6}$ Department of Visceral Surgery, Ambroise Paré Hospital, Assistance Publique-Hôpitaux de Paris (AP-HP), University Versailles-Saint-Quentin, Boulogne, France ${ }^{7}$ Department of Digestive and HepatoPancreato-Biliary Surgery, Pitié-Salpêtrière Hospital, Assistance Publique-Hôpitaux de Paris (AP-HP), Sorbonne Université, Paris, France ${ }^{8}$ Nutriomics Team, INSERM, UMRS U1166, Paris, France.
}

Funding agencies: This research was supported by grant AOR 09059 from the Programme Hospitalier de Recherche Clinique (PHRC, France).

Disclosure: The authors declared no conflict of interest.

Author contributions: JMO had full access to all of the data in the study and takes responsibility for the integrity of the data and the accuracy of the data analysis. Study concept and design: JMO and CC. Obtained funding: JMO. Study supervision: CC. Acquisition, analysis, or interpretation of data: CC, AB, CR, JLB, AT, KC, CP, and JMO. Performing the gastric bypass surgery: JLB and AT. Drafting of the manuscript: AB and JMO. Statistical analysis: CR. Critical revision of the manuscript for important intellectual content: CC, AB, CR, JLB, AT, KC, CP, and JMO.

Clinical trial registration: ClinicalTrials.gov identifier NCT01113996.

Additional Supporting Information may be found in the online version of this article. 
mass $(14,15)$. Bariatric surgery is also associated with a decrease in absolute muscle strength (16). However, when expressed relative to muscle mass, muscle strength was found unchanged, suggesting that the loss of absolute strength might be due to the decrease in muscle mass (8). The effect of resistance training, performed alone or in combination with endurance training, on changes in lean body mass and muscle strength during the first year after bariatric surgery has been assessed in only two RCTs $(8,9)$. Muscle strength was found to be improved in both studies $(8,9)$, whereas lean body mass was found preserved in one study (9) and unchanged in the other (8). Therefore, additional RCTs appear to be needed to further investigate the effectiveness and feasibility of resistance training in the bariatric surgery setting.

Strategies to preserve lean body mass during dietary-induced weight loss in patients with obesity include a combination of resistance training and a sufficient intake of high-quality protein (17). In the first months after bariatric surgery, energy and protein intake is dramatically reduced $(3,18)$. Emerging evidence has suggested that whey protein would help increase protein synthesis during energy deficit in patients with overweight or obesity (19). Whey protein, representing $20 \%$ of milk proteins, is rapidly digested with an early rise in blood amino acids and increased stimulation of muscle protein synthesis (20). The effect of additional protein intake in combination with exercise training after bariatric surgery is, however, not known.

The aim of this study was to determine whether resistance training with whey protein supplementation is effective in maintaining lean body mass and muscle strength 6 months after RYGB.

\section{Methods}

\section{Study design}

We undertook this single-center, open-label, parallel-group RCT between May 1, 2010, and December 31, 2014, at the Department of Nutrition of Pitié-Salpêtrière University Hospital (Assistance Publique-Hopitaux de Paris) in Paris, France. Patients were followed up for 6 months after surgery and underwent the same assessments at visits before and after surgery. The study was approved by the Ethics Committee of Pitié-Salpêtrière Hospital (Paris, France).

\section{Participants}

Bariatric surgery (RYGB) was offered to patients following current guidelines $(21,22)$. Inclusion criteria were female gender, age between 18 and 65 years, place of residence in Paris or its region, and BMI of $40 \mathrm{~kg} / \mathrm{m}^{2}$ or higher or BMI of $35 \mathrm{~kg} / \mathrm{m}^{2}$ or higher with at least one obesity comorbidity. Exclusion criteria were diagnosis of recent coronary event, uncontrolled hypertension, proliferative diabetic retinopathy or disabling neuropathy, dialysis treatment, orthopedic problems limiting exercise, abnormal cardiac stress test, ongoing or planned pregnancy, refusal to participate in a physical activity program, concurrent participation in a structured physical activity program, and food intolerance to milk protein products. All patients signed an informed written consent to join the study prior to surgery.

\section{Randomization}

We randomized patients at the time of surgery to receive usual care with regular medical and nutritional follow-up (control group [CON]), usual care and additional oral protein intake (protein group [PRO]), or usual care, additional protein intake, and supervised resistance training (protein plus exercise group [PRO+EX]).

\section{Procedures}

The same RYGB surgical procedure was performed laparoscopically with an alimentary limb of 1.2 to $1.5 \mathrm{~m}$ in length (14). All patients underwent detailed assessments before and 1, 3, and 6 months after surgery. At each visit, body weight and composition, dietary intake, and various blood parameters were assessed. Health-related quality of life was documented before and 3 and 6 months after surgery. Data on muscle strength, cardiorespiratory fitness, physical activity, and obesity comorbidities were collected before and 6 months after surgery.

Usual care. General dietary and physical activity counseling was provided to all participants during planned pre- and postsurgery visits at 1,3, and 6 months, as part of usual care (21). Dietary advice aimed to progressively increase protein intake to reach a minimum amount of $60 \mathrm{~g} / \mathrm{d}(2,3)$. Patients were encouraged to perform at least $150 \mathrm{~min} / \mathrm{wk}$ of moderate-to-vigorous endurance-type physical activity, such as brisk walking (12). All patients received the same initial prescription to prevent vitamin and mineral deficiencies (21), starting 15 days before surgery and including iron $(2 \times 80 \mathrm{mg} / \mathrm{d})$, calcium $(1,000 \mathrm{mg} / \mathrm{d})$, vitamin D (800 IU/d), and a multivitamin and mineral supplement. No other supplement was allowed throughout the study.

Whey protein supplementation. From the first week after surgery, patients randomized to the PRO and PRO+EX groups were prescribed a daily protein supplementation in the form of a whey-protein-enriched powder (Inkospor X-TREME; INKO, Peyruis, France) delivered in 750 -g cans to the participants' home by the supplier. Participants were instructed to consume two powder drinks a day, one in the morning and the other in the afternoon or evening, shortly after the end of the exercise session for the PRO+EX group, for a total supplemental whey protein dose of $48 \mathrm{~g} / \mathrm{d}$ (corresponding to two measuring spoons of 30 $\mathrm{g}$ of powder containing $24 \mathrm{~g}$ of whey protein mixed with $150 \mathrm{~mL}$ of water). Each protein drink provided approximately $464 \mathrm{~kJ}$ of energy, $0.9 \mathrm{~g}$ of sucrose, $1 \mathrm{~g}$ of fat, and $0.3 \mathrm{~g}$ of fiber. Patients were asked to return empty cans of protein powder at follow-up visits to assess compliance.

Resistance training program. From week 6 post surgery, participants randomized to the PRO+EX group exercised for 1 hour three times per week on nonconsecutive days over 18 weeks at our center under the supervision of qualified trainers. Each session included 10 minutes of light endurance warming up, 45 minutes of strength training, and 5 minutes of stretching and cooling down. The program was adapted from previous studies $(23,24)$ that demonstrated the safety and effectiveness on body composition of progressive resistance training in patients with obesity and/or type 2 diabetes. The program consisted of six different movements (leg press, leg extension, abdominal crunch, chest press, vertical traction, and biceps curl) involving major muscle groups. Each exercise was repeated in four sets of 8 to 12 repetitions. For all movements except abdominal crunch, repetition maximum or maximum weight that can be used to complete one repetition (1-RM) values estimated before surgery were used to define weight loads during exercise sessions. The starting level was eight repetitions at $50 \%$ of $1-\mathrm{RM}$. The number of repetitions was increased (from 8 to 9 to 12), and then weight loads were increased (from $50 \%$ 
to $65 \%$ to $75 \%$ of $1-\mathrm{RM})$. Resting periods between repetition sets were approximately 60 seconds.

Anthropometry and body composition. Body composition was measured by whole-body fan-beam dual-energy x-ray absorptiometry (DXA) scan (Hologic Discovery W; Hologic, Bedford, Massachusetts) (14). Lean body mass was calculated as weight minus bone mineral content minus fat mass. Body regions (upper limb, lower limb, trunk, and head) were delineated with the use of specific anatomical landmarks. For all patients, right-side half-body scans were carried out from which wholebody composition was extrapolated, as described (25).

Muscle strength. Isometric maximal grip strength was measured using a handgrip dynamometer (Jamar; Sammons Preston Rolyan, Bolingbrook, Canada) (26). The highest value of five maximal trials with each hand was kept for analyses (26). Dynamic maximal strength of lower and upper limbs was measured on strength training equipment (leg press, chest press) (27). After a warm-up set of ten repetitions with a light weight, subjects were asked to complete sets of three repetitions with the greatest strength and speed. Testing began at $50 \%$ of their estimated maximal strength, and the load was gradually increased for subsequent sets until failure was reached. The Myotest accelerometer device (Acceltec, Sion, Switzerland) is a valid and reliable tool specifically designed for field-based evaluation of muscle strength, velocity, and power $(28,29)$. During strength testing, the Myotest was laid flat on the weights that moved on the vertical plane. The Myotest measured the maximum velocity (centimeters per second), which we used to establish the load-velocity relationship. Given the linear relationship between load and velocity, the maximal load, i.e., load at zero velocity, can be estimated accurately using the load-velocity relationship (30). The 1-RM, which is a measure of dynamic strength, is then estimated using the following equation: $1-\mathrm{RM}=(0.871 \times$ load at zero velocity) -0.624 (30). For analysis, strength was expressed as absolute values (kilograms), values relative to body weight and lean body mass, and values adjusted for lean body mass.

Cardiorespiratory fitness and physical activity. $\mathrm{VO}_{2}$ peak was measured by indirect calorimetry during a graded maximal exercise test on a cycle ergometer (31). The test protocol started at a workload of $30 \mathrm{~W}$ and increased by $30 \mathrm{~W}$ every 2 minutes until volitional exhaustion. $\mathrm{VO}_{2}$ peak, determined as the highest attained $\mathrm{VO}_{2}$ during the test, was expressed in absolute values and relative to body mass and to lean body mass. For assessment of habitual physical activity, participants wore the Actigraph GT3X+ (ActiGraph, LLC, Pensacola, Florida) accelerometer for seven consecutive days during waking hours. Time wear of at least 4 days and at least 8 hours each day defined valid data (32). The number of counts per minute was calculated from movements on the vertical axis. Steps were calculated by censoring steps taken at intensity $<500$ counts per minute (33). Freedson cut points were used to quantify sedentary behavior and light-, moderate-, and vigorous-intensity physical activity (34).

Other assessments. Health-related quality of life was assessed with the 36-Item Short Form Health Survey (SF-36) and was summarized in a physical and a mental component score ranging from 0 (poor) to 100 (good) (35). Food and beverage consumption was assessed by a registered dietitian using the dietary history method (36). Energy (kilojoules per day) and macronutrient (grams per day) intakes were calculated using the national food database. Obesity comorbidities were defined through detailed assessment of each patient medical history and medication use (37). Blood samples were collected after an overnight fast to measure routine parameters (blood count, blood glucose, protein, prealbumin, albumin, $25-\mathrm{OH}$ vitamin D3, vitamin B12, folate, thiamine).

\section{Outcomes}

The primary outcome was pre- to 6-month postsurgery change in lean body mass. Secondary outcomes included changes in upper- and lower-limb muscle strength, cardiorespiratory fitness $\left(\mathrm{VO}_{2}\right.$ peak $)$, objectively assessed habitual physical activity, dietary protein intake, nutritional status, obesity comorbidities, and health-related quality of life.

\section{Statistical analysis}

Based on evidence available at the time the study was designed, it was estimated that subjects lost an average of $16(7.4) \%$ of their lean body mass 6 months after RYGB (14). Sample sizes were determined a priori and based on detection of a preservation effect in lean body mass loss of about one-third in subjects with protein supplementation (i.e., average loss of 10.7[4.9]\%) (38). We assumed a similar additional effect in subjects with strength training. Setting an overall power to $80 \%$ with $\alpha$ at 0.05 yielded an estimate of 75 patients (with 31 in PRO group, 22 in $\mathrm{PRO}+\mathrm{EX}$ and CON groups).

Characteristics of interest were summarized with frequencies and percentages for categorical data and means and standard deviations (SD), or medians and 25th and 75th percentiles $\left(\mathrm{P}_{25}-\mathrm{P}_{75}\right)$ for continuous data. Variables that did not meet the assumption of a normal distribution were log-transformed and retested. If the assumption of normality could not be met by transformation, we used nonparametric tests for comparing groups. Baseline preoperative characteristics were analyzed with one-way analysis of variance (ANOVA) or Kruskal-Wallis test (for continuous data) and $\chi^{2}$ test or Fisher exact test (for categorical data) as appropriate. Linear mixed models were used to estimate and test changes over time. The terms "group," "time," and "group $\times$ time" were included as fixed effects. Each follow-up wave was added to the model as a dummy variable. Changes in muscle strength independent of changes in regional lean mass were estimated by including the regional lean body mass variable as a covariate in the corresponding models. Primary analyses were intention-to-treat (ITT), involving all randomized patients $(n=76)$. For analyses of lower-limb muscle strength data, implausible values (1-RM values more than $320 \mathrm{~kg}$ ) led to exclusion of data from three subjects. All analyses were then repeated on completers defined as subjects taking $\geq 24 \mathrm{~g} / \mathrm{d}$ additional protein intake (i.e., half of total supplemental whey protein dose) and participating in $\geq 2$ exercise sessions per week for 16 weeks (i.e., the lower limit of prescribed exercise frequency). Two-sided $P$ values are reported. The dose-response relationship across randomized groups was examined by performing a test of trend and examining linear and nonlinear (quadratic) contrasts. Results were considered significant at $P<0.05$. Statistical analyses were performed with Stata software (release 13; Stata Corp., College Station, Texas).

\section{Results}

Out of 290 subjects assessed for eligibility, 71 patients were not included because they did not meet inclusion criteria, and 125 refused to 
participate (Figure 1). A total of 94 patients were included in the study; 76 were randomized to receive either usual follow-up (CON, $n=22)$, usual follow-up and additional protein intake (PRO, $n=31$ ) or usual follow-up, additional protein intake, and exercise training (PRO+EX, $n=23$ ) and included in the ITT analysis, with 47 of them meeting the definition of completers. In the PRO and PRO+EX groups, we found no difference between noncompleters $(n=29)$ and completers $(n=25)$ in baseline characteristics, except for protein intake.

Baseline characteristics were similar between groups (Table 1). Mean (SD) age was 42.4 (9.9) years, body weight was $116.2(16.2)$ $\mathrm{kg}$, BMI was 44.0 (5.8), and percent body fat was $50.1 \%(4.0 \%)$. Compared with nonincluded patients, those included had lower BMI (BMI in nonincluded patients: $46.6(6.4) ; P=0.002$ ) and had similar age (43.1 [12.6] years; $P=0.719)$. The median $\left(\mathrm{P}_{25}-\mathrm{P}_{75}\right)$ number of exercise training sessions attended in the PRO+EX group was 35 (15-40). The median $\left(\mathrm{P}_{25}-\mathrm{P}_{75}\right)$ whey protein supplementation was 20.8 (12.5-41.7) g/d in the PRO group and 36.5 (29.2-41.7) g/d in the PRO+EX group. At baseline, five participants reached the physical activity threshold of $150 \mathrm{~min} /$ wk of 10-minute bouts of moderate-to-vigorous physical activity (one from the CON group and four from the PRO group).
Table 2 and Table 3 show changes in anthropometry and body composition, muscle strength, cardiorespiratory fitness, habitual physical activity, quality of life, dietary intake, and nutritional status after RYGB according to treatment groups in ITT analysis (Table 2) and in completers only (Table 3). A significant time effect was observed for almost all variables, both in ITT and completers. Overall, 6 months after RYGB, lean body mass decreased by 8.2 (SD 3.1) kg in parallel with a decrease in body weight, BMI, and fat mass (mean [SD], 27.5 [7.4] kg, 10.4 [2.6] kg/m², and 19.6 [4.8] kg, respectively) without significant difference between groups. For lower-limb and upper-limb strength in ITT analysis, when expressed relative to body weight or to lean body mass, there was a significant group effect and group $\times$ time interaction. In completers, group $\times$ time interaction was significant for lower-limb and upper-limb muscle strength expressed in absolute and relative values. In completers, a dose-response relationship was evidenced for changes in lower- and upper-limb 1-RM between CON, $\mathrm{PRO}$, and PRO+EX groups $\left(P_{\text {linear }}<0.05\right)$. Supporting Information Table $\mathrm{S} 1$ shows details of changes in dietary intakes.

Figure 2 illustrates the relative change in lower-limb and upper-limb muscle strength in percent change from baseline in completers. In the PRO+EX group after RYGB, increases in muscle strength were

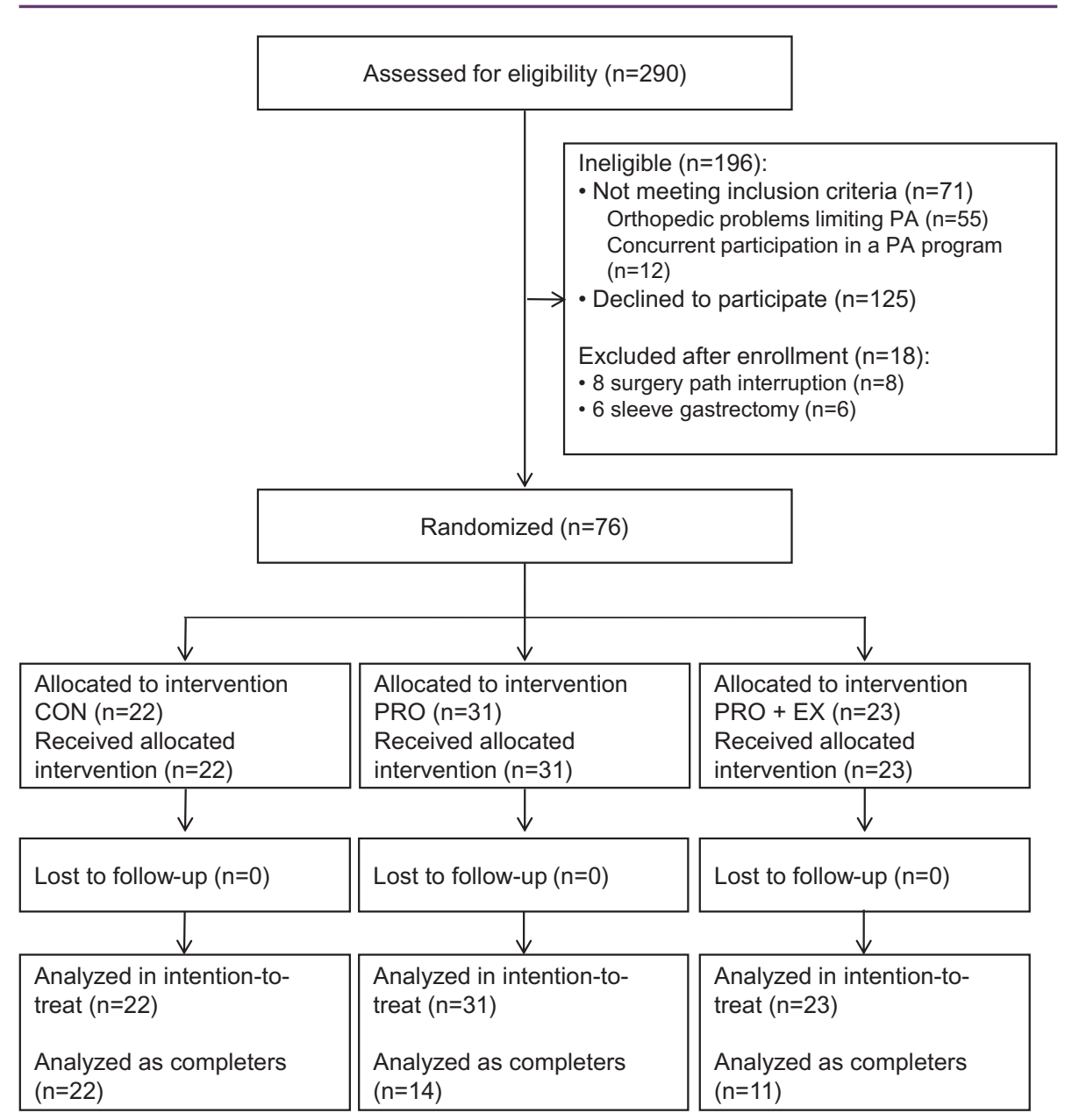

Figure 1 Study flow diagram. Abbreviations: CON, control group; PA, physical activity; PRO, protein intake group; $\mathrm{PRO}+\mathrm{EX}$, protein intake and supervised strength training group. 


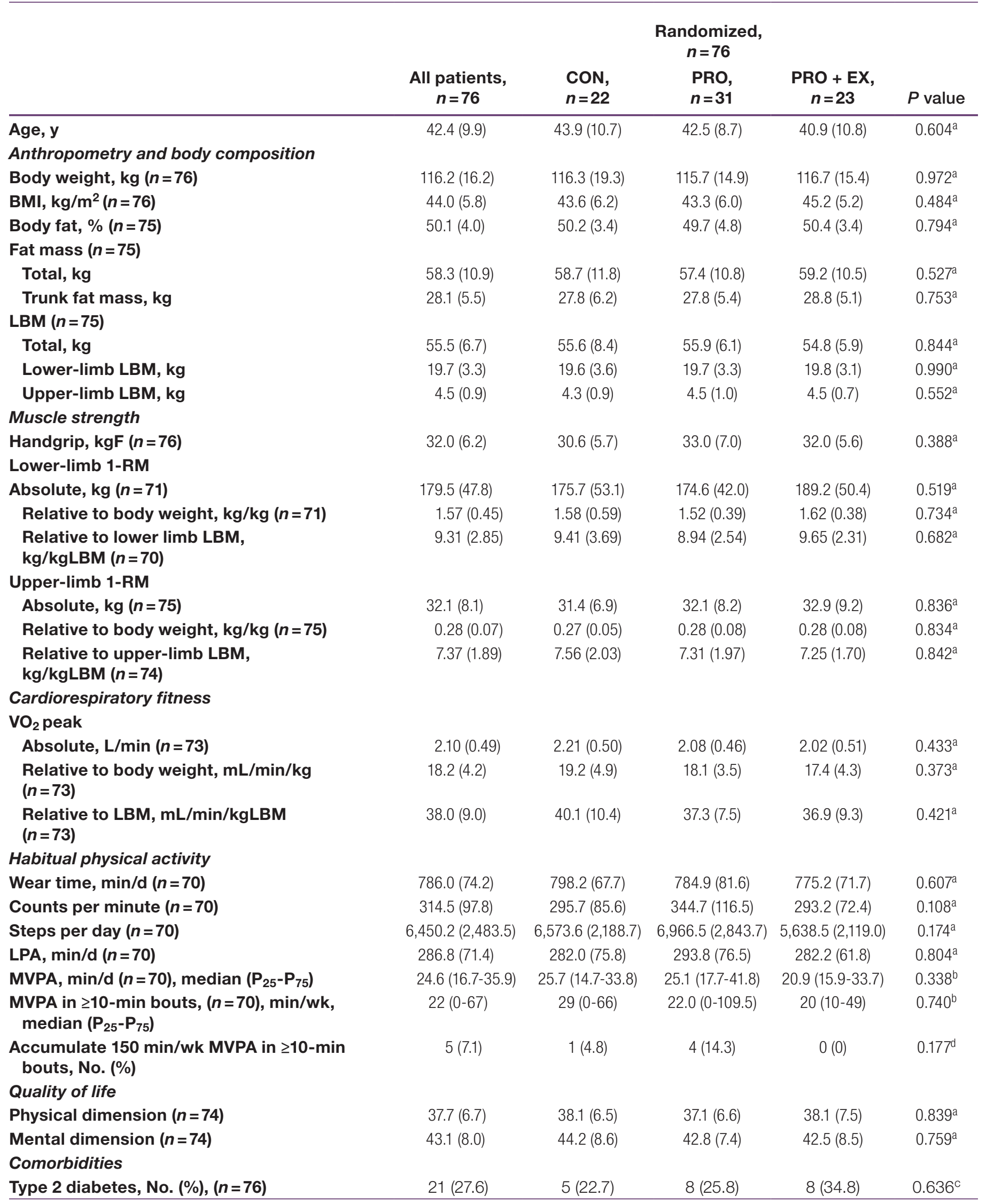




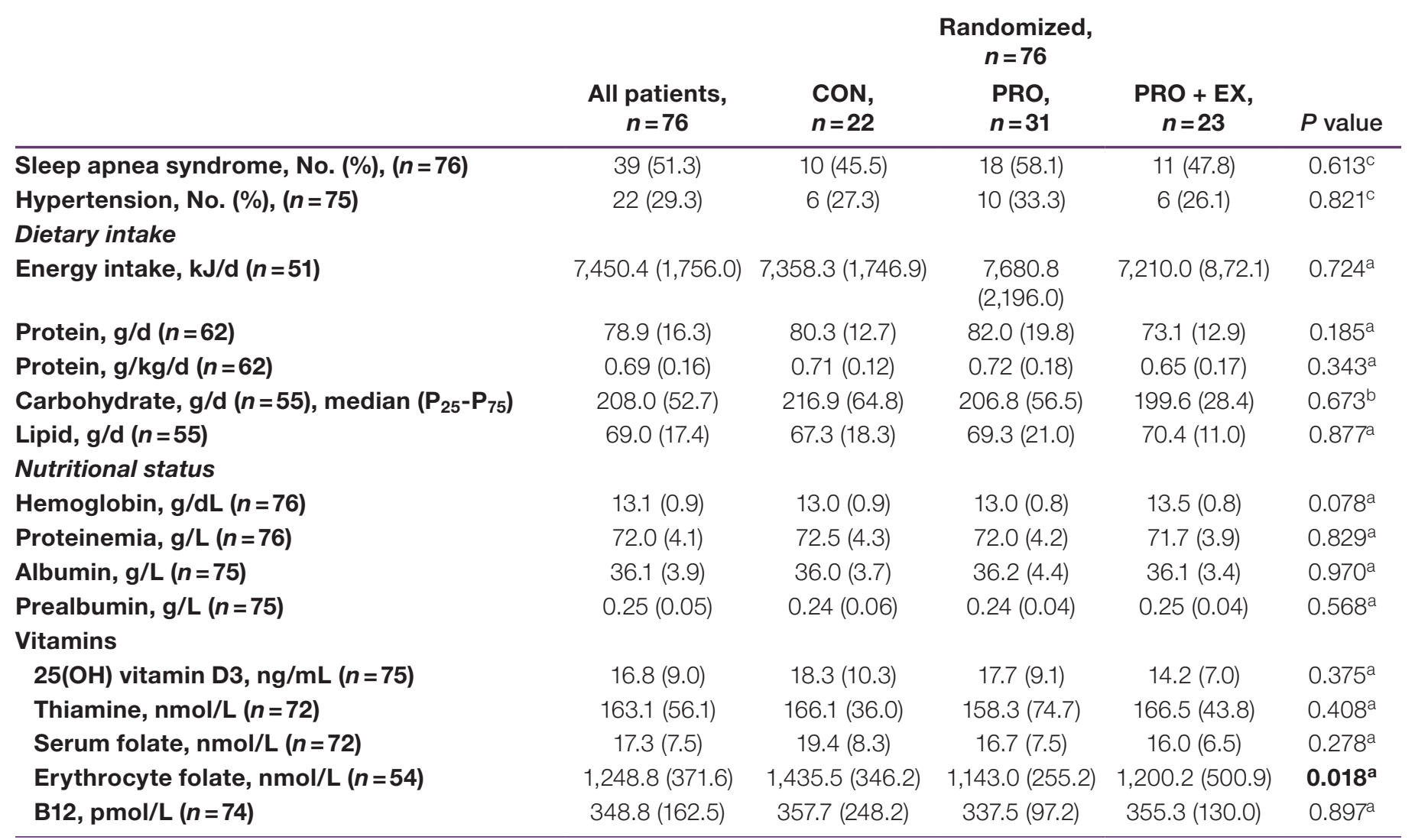

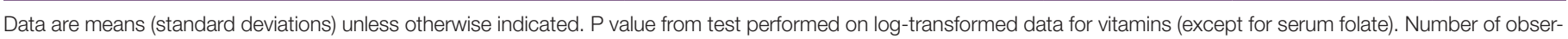
vations for each item may vary because of missing data.

ap value from one-way ANOVA.

${ }^{b} P$ value from Kruskal-Wallis test.

${ }^{\mathrm{c}} P$ value from $\chi^{2}$ test.

$\mathrm{d} P$ value from Fisher exact test.

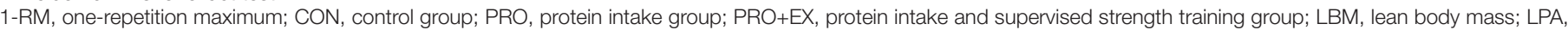
light physical activity; MVPA, moderate-to-vigorous physical activity; No., frequency; $n$, number of observations; $P_{x}$, xth percentile.

$12 \%$ and $13 \%$ in absolute values and $43 \%$ and $44 \%$ relative to body weight for lower and upper limb, respectively (Figure 2). When muscle strength was expressed relative to lean body mass, increases equaled $33 \%$ and $30 \%$.

Overall, 6 months after RYGB, $\mathrm{VO}_{2}$ peak increased by 2.8 (SD 4.9) $\mathrm{mL} / \mathrm{kg} / \mathrm{min}$ and the number of steps by 1,178 (SD 3,082) steps per day. A significant time effect without difference between groups was also observed for changes in handgrip strength, energy, macronutrient intake, and nutritional parameters. Mean (SD) daily protein intake (including the additional protein intake) 6 months after RYGB was 60.2 (17.3), 74.5 (22.4), and 81.4 (27.7) g/d in CON, PRO, and PRO+EX subjects, respectively. No serious adverse effect was recorded.

\section{Discussion}

This is the first RCT to test whether resistance training, under supervision for 18 weeks and with protein supplementation in the form of oral intake of whey protein added to the usual diet, was effective in maintaining lean body mass after RYGB. Although body composition changes did not differ across groups, other results show an increase in muscle strength, which was found to be two to three times higher for lower limbs in the group following the exercise training program and the protein supplementation compared with the group with protein supplementation without exercise and with the group that followed the usual postsurgery medical and nutritional care.

Results also show that surgery-induced weight loss by itself was associated with a series of beneficial health effects, including increased objectively measured habitual physical activity and cardiorespiratory fitness, adding to current evidence indicating an overall improved cardiovascular risk profile in patients after bariatric surgery. Postsurgery improvement in cardiorespiratory fitness has been previously reported in several observational studies (39). Changes in habitual physical activity, however, are still a matter of discussion. According to recent reviews, data generated from self-reported questionnaires consistently indicated an increase in physical activity, whereas data from objective measures indicated no change or only modest increases $(5,16,40)$.

A unique feature of our trial is the design combining muscle strength training and protein supplementation in patients undergoing bariatric surgery. At the time the study was designed and funded, no RCT had 
TABLE 2 Changes in anthropometry, body composition, muscle strength, cardiorespiratory fitness, habitual physical activity, and quality of life after Roux-en-Y gastric bypass surgery (intention-to-treat, $n=76$ )

\begin{tabular}{|c|c|c|c|c|c|c|}
\hline & \multicolumn{3}{|c|}{ Change from baseline $(95 \% \mathrm{CI})$} & \multicolumn{3}{|c|}{$P$} \\
\hline & $\begin{array}{l}\text { CON, } \\
n=22\end{array}$ & $\begin{array}{l}\text { PRO, } \\
n=31\end{array}$ & $\begin{array}{c}\text { PRO+EX, } \\
n=23\end{array}$ & Group & Time & $\begin{array}{l}\text { Group } x \\
\text { time }\end{array}$ \\
\hline \multicolumn{7}{|l|}{$\begin{array}{l}\text { Anthropometry and body } \\
\text { composition }\end{array}$} \\
\hline Body weight, kg & $-28.0(-30.6$ to -25.4$)$ & $-27.2(-29.4$ to -25.1$)$ & $-27.4(-29.9$ to -24.8$)$ & 0.970 & $<0.001$ & 0.664 \\
\hline BMI, $\mathbf{k g} / \mathrm{m}^{2}$ & $-10.5(-11.4$ to -9.6$)$ & $-10.2(-11.0$ to -9.4$)$ & $-10.6(-11.5$ to -9.7$)$ & 0.503 & $<0.001$ & 0.686 \\
\hline Fat mass, kg & $-19.7(-21.5$ to -17.9$)$ & $-19.8(-21.3$ to -18.2$)$ & $-19.4(-21.1$ to -17.6$)$ & 0.808 & $<0.001$ & 0.417 \\
\hline LBM, kg & $-8.8(-10.1$ to -7.5$)$ & $-8.2(-9.3$ to -7.1$)$ & $-7.7(-9.0$ to -6.5$)$ & 0.803 & $<0.001$ & 0.899 \\
\hline Lower-limb LBM, kg & $-3.6(-4.3$ to -3.0$)$ & $-3.0(-3.6$ to -2.5$)$ & $-3.2(-3.8$ to -2.6$)$ & 0.712 & $<0.001$ & 0.557 \\
\hline Upper-limb LBM, kg & $-0.3(-0.6$ to -0.1$)$ & $-0.3(-0.5$ to -0.1$)$ & $-0.5(-0.8$ to -0.3$)$ & 0.633 & $<0.001$ & 0.554 \\
\hline \multicolumn{7}{|l|}{ Muscle strength } \\
\hline Handgrip, kgF & $-21.0(-43.1$ to 1.1$)$ & $-29.1(-47.5$ to -10.6$)$ & $-22.9(-44.1$ to -1.4$)$ & 0.427 & $<0.001$ & 0.840 \\
\hline \multicolumn{7}{|c|}{ 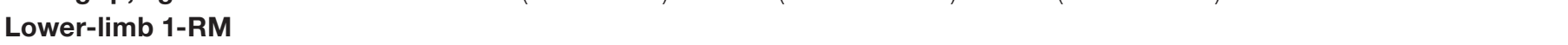 } \\
\hline Absolute, $\mathbf{k g}$ & $-30.4(-55.8$ to -5.0$)$ & $-19.6(-41.5$ to 2.3$)$ & +4.68 (-19.6 to 28.9) & 0.012 & 0.032 & 0.128 \\
\hline $\begin{array}{l}\text { Relative to body weight, } \\
\mathrm{kg} / \mathrm{kg}\end{array}$ & $+0.12(-0.14$ to 0.38$)$ & $+0.22(-0.01$ to 0.44$)$ & +0.59 (0.34 to 0.84$)$ & 0.033 & $<0.001$ & 0.021 \\
\hline $\begin{array}{l}\text { Relative to lower-limb LBM, } \\
\text { kg/kgLBM }\end{array}$ & -0.08 (-1.53 to 1.38$)$ & $+0.19(-1.08$ to 1.46$)$ & +2.22 (0.83 to 3.60$)$ & 0.041 & 0.055 & 0.043 \\
\hline $\begin{array}{l}\text { Adjusted for lower-limb LBM, } \\
\text { kg }\end{array}$ & $-19.3(-46.3$ to 7.7$)$ & $-9.1(-32.3$ to 14.2$)$ & $+14.6(-10.9$ to 40.2$)$ & 0.010 & 0.584 & 0.136 \\
\hline \multicolumn{7}{|l|}{ Upper-limb 1-RM } \\
\hline Absolute, kg & $-6.2(-9.9$ to -2.6$)$ & $-4.8(-7.9$ to -1.7$)$ & $-0.5(-4.0$ to 3.0$)$ & 0.135 & $<0.001$ & 0.061 \\
\hline $\begin{array}{l}\text { Relative to body weight, } \\
\mathrm{kg} / \mathrm{kg}\end{array}$ & $+0.02(-0.02$ to 0.06$)$ & $+0.03(-0.01$ to 0.06$)$ & +0.09 (0.05 to 0.12$)$ & 0.175 & $<0.001$ & 0.050 \\
\hline $\begin{array}{l}\text { Relative to upper-limb LBM, } \\
\mathrm{kg} / \mathrm{kgLBM}\end{array}$ & $-1.0(-2.0$ to -0.1$)$ & $-0.8(-1.6$ to 0.1$)$ & $+0.9(-0.1$ to 1.9$)$ & 0.242 & 0.272 & 0.010 \\
\hline $\begin{array}{l}\text { Adjusted for upper-limb LBM, } \\
\text { kg }\end{array}$ & $-5.2(-9.0$ to -1.5$)$ & $-4.1(-7.3$ to 0.9$)$ & $+1.2(-2.5$ to 4.9$)$ & 0.123 & 0.012 & 0.029 \\
\hline \multicolumn{7}{|l|}{ Cardiorespiratory fitness } \\
\hline \multicolumn{7}{|l|}{$\mathrm{VO}_{2}$ peak } \\
\hline Absolute, L/min & $-0.4(-0.6$ to -0.2$)$ & $-0.3(-0.4$ to -0.1$)$ & $-0.1(-0.3$ to 0.1$)$ & 0.759 & $<0.001$ & 0.276 \\
\hline $\begin{array}{l}\text { Relative to body weight, } \\
\mathrm{mL} / \mathrm{min} / \mathrm{kg}\end{array}$ & $+1.8(-0.3$ to 3.9$)$ & $+2.5(0.7$ to 4.3$)$ & $+4.0(1.9$ to 6.1$)$ & 0.764 & $<0.001$ & 0.324 \\
\hline $\begin{array}{l}\text { Relative to LBM, } \\
\mathrm{mL} / \mathrm{min} / \mathrm{kgLBM}\end{array}$ & $-1.0(-5.1$ to 3.1$)$ & $+0.4(-3.1$ to 3.8$)$ & $+3.2(-0.8$ to 7.3$)$ & 0.663 & 0.443 & 0.335 \\
\hline \multicolumn{7}{|l|}{ Habitual physical activity } \\
\hline Wear time, $\mathrm{min} / \mathrm{d}$ & $-7.5(-45.7$ to 30.6$)$ & $-3.0(-36.4$ to 30.4$)$ & $-8.3(-46.5$ to 29.8$)$ & 0.551 & 0.561 & 0.975 \\
\hline Counts per minute & $+49.4(-0.1$ to 98.9$)$ & $+10.7(-32.9$ to 54.4$)$ & $+31.0(-18.5$ to 80.5$)$ & 0.337 & 0.031 & 0.515 \\
\hline Steps per day & +1,716 (358 to 3,074) & +629 (-560 to 1,819) & $+1,022(-336$ to 2,379$)$ & 0.164 & 0.004 & 0.496 \\
\hline LPA, $\min / d$ & +3.1 (-26.5 to 32.6) & $-23.7(-49.7$ to 2.3$)$ & $+1.5(-28.1$ to 31.0$)$ & 0.995 & 0.445 & 0.311 \\
\hline MVPA, min/d & +9.6 (1.9 to 17.3$)$ & $+5.7(-1.1$ to 12.5$)$ & $+5.7(-2.0$ to 13.5$)$ & 0.178 & 0.001 & 0.717 \\
\hline MVPA in $\geq 10-\mathrm{min}$ bouts, $\mathrm{min} / \mathrm{wk}$ & +30.5 (1.2 to 59.9$)$ & $+20.3(-5.7$ to 46.4$)$ & $+14.8(-14.6$ to 44.1$)$ & 0.114 & 0.009 & 0.751 \\
\hline \multicolumn{7}{|c|}{ Quality of life } \\
\hline Physical dimension & +8.7 (6.1 to 11.2$)$ & $+9.4(7.2$ to 11.6$)$ & +10.0 (7.4 to 12.7$)$ & 0.994 & $<0.001$ & 0.438 \\
\hline Mental dimension & $+5.8(2.3$ to 9.3$)$ & $+8.2(5.3$ to 11.2$)$ & $+8.9(5.3$ to 12.4$)$ & 0.929 & $<0.001$ & 0.800 \\
\hline \multicolumn{7}{|l|}{ Dietary intake } \\
\hline Energy intake, kJ/d & $\begin{array}{c}-2,196.2(-2,920.7 \text { to } \\
-1,471.7)\end{array}$ & $\begin{array}{c}-2,737.2(-3,362.6 \text { to } \\
-2,111.8)\end{array}$ & $\begin{array}{c}-1,961.9(-2,715.4 \text { to } \\
-1,208.5)\end{array}$ & 0.492 & $<0.001$ & 0.526 \\
\hline Protein, g/d & $-20.8(-30.7$ to -10.9$)$ & $-8.2(-16.5$ to 0.1$)$ & $+7.3(-2.6$ to 17.1$)$ & $<0.001$ & $<0.001$ & $<0.001$ \\
\hline
\end{tabular}




\begin{tabular}{|c|c|c|c|c|c|c|}
\hline & \multicolumn{3}{|c|}{ Change from baseline $(95 \% \mathrm{Cl})$} & \multicolumn{3}{|c|}{$\boldsymbol{P}$} \\
\hline & $\begin{array}{l}\text { CON, } \\
n=22\end{array}$ & $\begin{array}{l}\text { PRO, } \\
n=31\end{array}$ & $\begin{array}{c}\text { PRO+EX, } \\
n=23\end{array}$ & Group & Time & $\begin{array}{l}\text { Group } x \\
\text { time }\end{array}$ \\
\hline Protein, g/kg/d & $-0.18(-0.28$ to -0.09$)$ & $-0.07(-0.15$ to 0.01$)$ & $+0.06(-0.03$ to 0.16$)$ & $<0.001$ & $<0.001$ & $<0.001$ \\
\hline Carbohydrate, g/d & $-75.5(-100.1$ to -50.9$)$ & $-79.1(-101.1$ to -57.1$)$ & $\begin{array}{c}-79.1(-104.4 \text { to } \\
-53.8)\end{array}$ & 0.204 & $<0.001$ & 0.954 \\
\hline Lipid, g/d & $-19.6(-27.0$ to -12.2$)$ & $-26.3(-32.9$ to -19.7$)$ & $-23.1(-30.7$ to -15.4$)$ & 0.813 & $<0.001$ & 0.714 \\
\hline \multicolumn{7}{|l|}{ Nutritional status } \\
\hline Hemoglobin, g/dL & $-0.01(-0.38$ to 0.36$)$ & $-0.04(-0.35$ to 0.28$)$ & $-0.02(-0.39$ to 0.35$)$ & 0.030 & 0.150 & 0.937 \\
\hline Proteinemia, g/L & $-2.0(-3.7$ to -0.3$)$ & $-1.6(-3.0$ to -0.1$)$ & $-2.0(-3.7$ to -0.4$)$ & 0.820 & $<0.001$ & 0.837 \\
\hline Albumin, $g / L$ & $+1.1(-0.5$ to 2.6$)$ & +1.5 (0.2 to 2.8$)$ & $+1.0(-0.6$ to 2.5$)$ & 0.829 & 0.001 & 0.791 \\
\hline Prealbumin, g/L & $-0.05(-0.07$ to -0.04$)$ & $-0.05(-0.06$ to -0.04$)$ & $-0.05(-0.07$ to -0.04$)$ & 0.400 & $<0.001$ & 0.964 \\
\hline \multicolumn{7}{|c|}{ (2) } \\
\hline 25(OH) Vitamin D3, ng/mL & +11.4 (7.1 to 15.7$)$ & +12.8 (9.2 to 16.4$)$ & $+17.6(13.5$ to 21.8$)$ & 0.991 & $<0.001$ & 0.341 \\
\hline Thiamine, nmol/L & +9.9 (-28.0 to 47.8$)$ & +38.3 (10.0 to 66.7) & +38.9 (8.0 to 69.9) & 0.119 & 0.007 & 0.445 \\
\hline Serum folate, nmol/L & $+3.3(-0.2$ to 6.9$)$ & +4.9 (1.9 to 8.0) & +10.7 (7.1 to 14.3$)$ & 0.504 & $<0.001$ & 0.047 \\
\hline Erythrocyte folate, nmol/L & +37.7 (-159.7 to 235.2) & +230.5 (60.5 to 400.5) & $\begin{array}{c}\text { +398.8 (180.4 to } \\
617.2)\end{array}$ & 0.268 & $<0.001$ & 0.192 \\
\hline B12, pmol/L & $-84.9(-131.5$ to-38.3) & $-62.1(-101.7$ to -22.6$)$ & $-86.5(-133.6$ to -39.5$)$ & 0.947 & $<0.001$ & 0.777 \\
\hline
\end{tabular}

$P$ values for group, time, and interaction (group $\times$ time) terms in mixed models; bold values indicate significance with $P<0.05$.

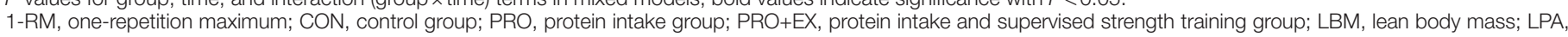
light physical activity; MVPA, moderate-to-vigorous physical activity.

TABLE 3 Changes in anthropometry, body composition, muscle strength, cardiorespiratory fitness, habitual physical activity and quality of life after Roux-en-Y gastric bypass surgery (completers, $n=47$ )

\begin{tabular}{|c|c|c|c|c|c|c|}
\hline & \multicolumn{3}{|c|}{ Change from baseline $(95 \% \mathrm{Cl})$} & \multicolumn{3}{|c|}{$\boldsymbol{P}$} \\
\hline & $\begin{array}{l}\text { CON, } \\
n=22\end{array}$ & $\begin{array}{l}\text { PRO, } \\
n=14\end{array}$ & $\begin{array}{c}\text { PRO+EX, } \\
n=11\end{array}$ & Group & Time & $\begin{array}{l}\text { Group } \\
\text { x time }\end{array}$ \\
\hline \multicolumn{7}{|l|}{$\begin{array}{l}\text { Anthropometry and body } \\
\text { composition }\end{array}$} \\
\hline Body weight, kg & $-28.0(-30.8$ to -25.2$)$ & $-26.7(-30.2$ to -23.1$)$ & $-25.7(-29.7$ to -21.8$)$ & 0.760 & $<0.001$ & 0.751 \\
\hline BMI, $\mathrm{kg} / \mathrm{m}^{2}$ & $-10.5(-11.4$ to -9.5$)$ & $-10.2(-11.4$ to -9.0$)$ & $-10.1(-11.5$ to -8.7$)$ & 0.291 & $<0.001$ & 0.811 \\
\hline Fat mass, kg & $-19.7(-21.5$ to -17.9$)$ & $-19.6(-21.9$ to -17.3$)$ & $-17.4(-20.0$ to -14.8$)$ & 0.513 & $<0.001$ & 0.362 \\
\hline Lean body mass, kg & $-8.8(-10.2$ to -7.5$)$ & $-7.2(-8.8$ to -5.5$)$ & $-7.8(-9.7$ to -5.9$)$ & 0.771 & $<0.001$ & 0.624 \\
\hline Lower-limbs LBM, kg & $-3.6(-4.3$ to -3.0$)$ & $-2.7(-3.5$ to -1.9$)$ & $-3.3(-4.2$ to -2.4$)$ & 0.695 & $<0.001$ & 0.318 \\
\hline Upper-limbs LBM, kg & $-0.3(-0.6$ to -0.1$)$ & $-0.2(-0.5$ to 0.1$)$ & $-0.6(-0.9$ to 0.2$)$ & 0.524 & $<0.001$ & 0.798 \\
\hline \multicolumn{7}{|l|}{ Muscle strength } \\
\hline Handgrip, kgF & $-21.0(-46.3$ to 4.3$)$ & $-28.0(-59.0$ to 3.0$)$ & $-3.6(-38.5$ to 31.4$)$ & 0.055 & 0.052 & 0.577 \\
\hline \multicolumn{7}{|l|}{ Lower-limb 1-RM } \\
\hline Absolute, $\mathbf{k g}$ & $-30.4(-54.8$ to -6.0$)$ & $-31.5(-64.7$ to 1.6$)$ & $+17.6(-15.5$ to 50.8$)$ & 0.007 & 0.100 & 0.048 \\
\hline $\begin{array}{l}\text { Relative to body weight, } \\
\mathrm{kg} / \mathrm{kg}\end{array}$ & $+0.12(-0.11$ to 0.35$)$ & $+0.11(-0.20$ to 0.43$)$ & +0.68 (0.37 to 0.99) & 0.071 & $<0.001$ & 0.010 \\
\hline $\begin{array}{l}\text { Relative to lower-limb } \\
\text { LBM, } \\
\text { kg/kgLBM }\end{array}$ & $-0.07(-1.36$ to 1.22$)$ & $-0.66(-2.41$ to 1.09$)$ & +3.10 (1.35 to 4.85$)$ & 0.066 & 0.097 & 0.005 \\
\hline $\begin{array}{l}\text { Adjusted for lower-limb } \\
\text { LBM, kg }\end{array}$ & $-18.7(-45.0$ to 7.6$)$ & $-23.4(-56.2$ to 9.4$)$ & $+28.7(-5.0$ to 62.5$)$ & 0.012 & 0.661 & 0.032 \\
\hline \multicolumn{7}{|l|}{ Upper-limb 1-RM } \\
\hline Absolute, kg & $-6.2(-9.9$ to -2.6$)$ & $-6.0(-10.7$ to -1.3$)$ & $+3.5(-1.6$ to 8.6$)$ & 0.002 & 0.028 & 0.006 \\
\hline Relative to body weight, & $+0.02(-0.02$ to 0.06$)$ & $+0.02(-0.03$ to 0.07$)$ & +0.13 (0.07 to 0.18) & 0.012 & $<0.001$ & 0.006 \\
\hline
\end{tabular}
$\mathrm{kg} / \mathbf{k g}$ 


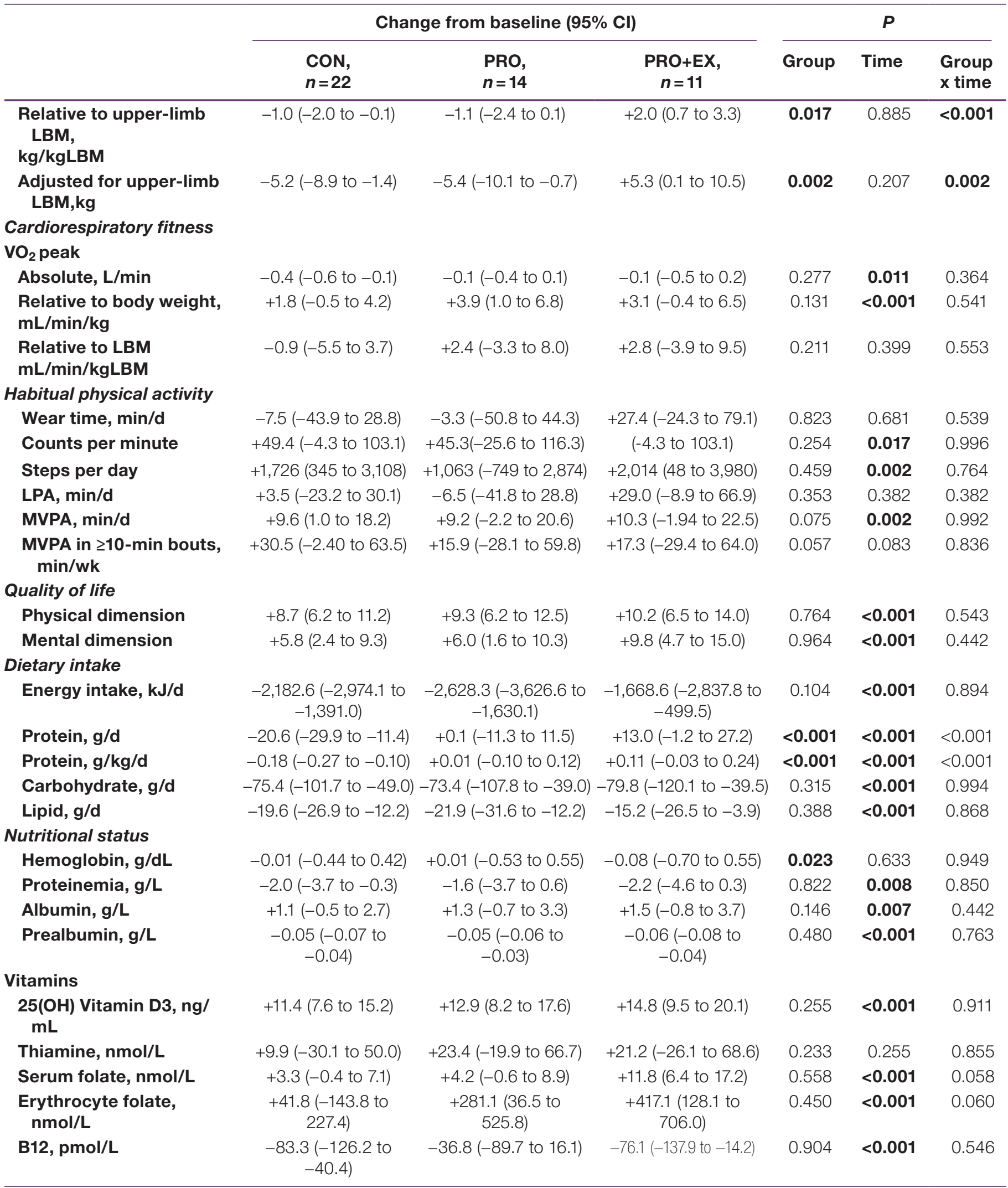

$P$ values for group, time, and interaction (group $\times$ time) terms in mixed models; bold values indicate significance with $P<0.05$.

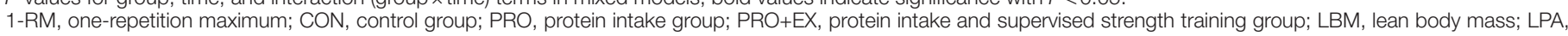
light physical activity; MVPA, moderate-to-vigorous physical activity. 


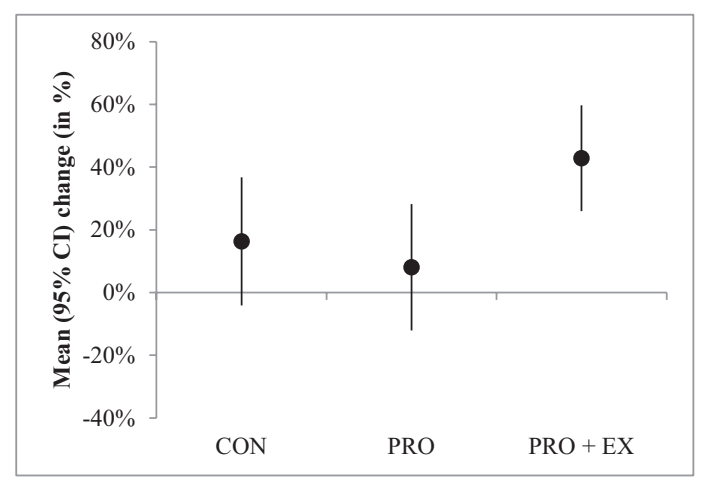

A. Lower limb muscle strength relative to body weight

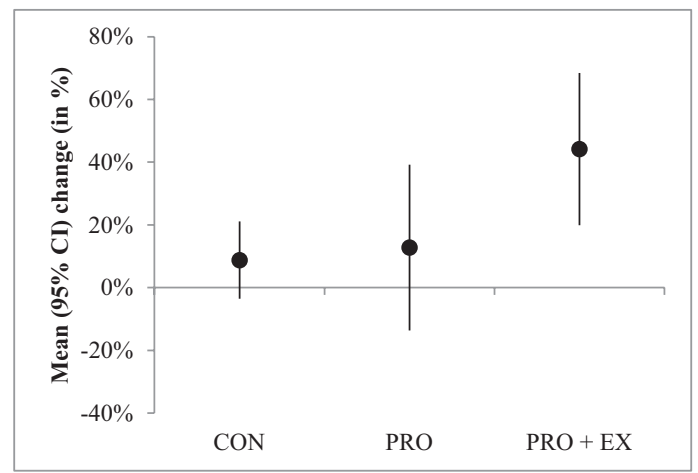

B. Upper limb muscle strength relative to body weight

Figure 2 Percent change in (A) lower-limb muscle strength and (B) upper-limb muscle strength relative to body weight from baseline to 6 months after Roux-en-Y gastric bypass surgery (completers). Dots represent mean values, and vertical bars extending from dots in both directions represent 95\% Cl. Abbreviations: CON, control group; $\mathrm{PRO}$, protein intake group; $\mathrm{PRO}+\mathrm{EX}$, protein intake and supervised strength training group.

been published testing the effects of exercise training, whatever type, on health outcomes after bariatric surgery. We initially focused on changes in lean body mass based on results of our previous observational study describing changes in body composition through serial DXA assessments after RYGB (14). In that study, in patients closely monitored and following usual care recommendations $(21,22)$, lean body mass loss amounted to about one-third of body weight loss in the 6-month to 1-year time period after RYGB (14). In addition to functional consequences, risk of malnutrition, and reduced capacity to cope with aggression, this loss in lean body mass would induce a decrease in energy expenditure, possibly contributing to weight regain as observed in many patients at long term after surgery (3). Since then, results of several trials have suggested similar changes in lean body mass with exercise training compared with usual care after bariatric surgery (5), in line with the present data. None of these previous trials has, however, investigated the effects of combining strength training with additional protein intake. Indeed, sufficient intake of high-quality protein is necessary to preserve or increase lean body mass through strength training (17). This also explains why we decided not to include an exercise-only group in our trial.

A recent review evidenced decreased muscle strength after bariatric surgery (16). Interestingly, our findings show that gains in muscle strength can be achieved in the first months following bariatric surgery with progressive moderate-intensity strength training. This gain in muscle strength is likely to be a beneficial effect regarding physical functioning given the major contribution of muscle strength in performing daily living physical activity in persons with obesity (41). In the PRO+EX group, we observed an increase of $12 \%$ and $43 \%$ on average in lower-limb muscle strength in absolute and relative terms, respectively. Such an increase in absolute strength is lower than that usually reported after resistance training in previously untrained women (42) but is comparable to the gain observed after resistance training following bariatric surgery (8). In a nonrandomized trial, Daniels et al. reported an $18 \%$ to $36 \%$ increase in lower-limb absolute strength after a 12-week resistance training. Increases in muscle strength of approximately $20 \%$ also were found after resistance training when performed during dietary-induced weight loss (43). The decrease in lean body mass associated with weight loss might prevent large gains in absolute strength, and even more so during surgery-induced weight loss. Our findings therefore add to emerging evidence showing that it is feasible to substantially increase muscle strength with physical training, even during marked negative energy balance, leading to important lean body mass loss. This increase in muscle strength was not associated with additional improvements in quality of life, in line with previous studies (44).

Gains in muscle strength as found here might be attributable to neural adaptations rather than muscle hypertrophy. Neural adaptations occurring during the first months of resistance training mainly include increased motor unit activation of the trained muscles and decreased cocontraction of antagonists (10). Uncoupling between muscle strength and mass after long-term resistance training has been well described (10). For example, a 66\% increase in strength after a 6-month strength training program performed in middle-aged women under normocaloric conditions was explained by a $34 \%$ increase in muscle activation and a $9 \%$ increase in muscle cross section (42).

Protein intake appeared sufficient to maintain protein status, although it was found insufficient to observe an effect on lean body mass. In the control group, energy and protein intakes were indeed very low during the first months after surgery, in agreement with previous literature (3). With the use of a whey protein supplement, subjects in the two intervention groups achieved increased protein intake compared with usual care. Protein intake was, on average, more than $60 \mathrm{~g} / \mathrm{d} 3$ months after RYGB, which corresponds to thresholds suggested in recent guidelines for bariatric surgery patients $(2,3)$. This was, however, far from recommended protein intake for maintenance of muscle mass during strength training, which typically exceeds $1 \mathrm{~g} / \mathrm{kg} / \mathrm{d}$ (45). The very low protein intake in a context of marked negative energy balance would be a main reason to explain the absence of a significant effect on lean body mass, which was our main hypothesis. Whey protein is known to induce higher increases in muscle protein synthesis compared with other proteins (20). During previous studies of dietary-induced weight loss, whey protein supplementation led to lean mass retention, though the effect size was modest (22). The effect of whey protein on muscle metabolism during negative energy balance as seen after bariatric surgery has not been investigated.

Strengths of the present RCT include the supervised and progressive strength training program, the homogeneous sample, the objective assessment of a large set of health outcomes that were found favorably associated with surgery-induced weight loss, and the careful follow-up of patients at prespecified postsurgery time points that were the same for 
all patients. Some limitations should be noted. Adherence to additional protein intake was self-reported. We included only women, and similar investigations should also be performed in men. Mean BMI was higher in nonincluded subjects, which might limit the generalizability of findings. Our assessment of muscle mass was indirect as it was based on DXAmeasured lower-limb lean body mass. Since this trial was designed, the number of sleeve gastrectomy procedures has risen sharply (3). Whether our results also apply to different bariatric procedures would need to be studied.

\section{Conclusion}

This trial shows that significant improved muscle strength was achieved through the combination of resistance training and additional protein intake for 6 months after RYGB. Although no difference was found regarding weight and lean body mass loss or improvement in cardiorespiratory fitness after bariatric surgery, these findings add to the body of knowledge indicating the adjunct value of physical exercise training in the follow-up care of bariatric surgery in patients with severe obesity. $\mathbf{O}$

\section{Acknowledgments}

The authors would like to thank the Unite de Recherche Clinique (URC) of Pitie-Salpetriere Hospital in Paris, France, for expert help and support in conducting this study. Individual participant data or any other data will not be available.

\section{(C) 2018 The Obesity Society}

\section{References}

1. Sjostrom L, Narbro K, Sjostrom CD, et al. Effects of bariatric surgery on mortality in Swedish obese subjects. N Engl J Med 2007:357:741-752.

2. Mechanick JI, Youdim A, Jones DB, et al. Clinical practice guidelines for the perioperative nutritional, metabolic, and nonsurgical support of the bariatric surgery patient-2013 update: cosponsored by American Association of Clinical Endocrinologists, The Obesity Society, and American Society for Metabolic \& Bariatric Surgery. Obesity (Silver Spring) 2013;21(suppl 1):S1-27.

3. Mingrone G, Bornstein S, Le Roux CW. Optimisation of follow-up after metabolic surgery. Lancet Diabetes Endocrinol 2018;6:487-499.

4. Jensen MD, Ryan DH, Donato SM, et al. Executive summary: guidelines (2013) for the management of overweight and obesity in adults: a report of the American College of Cardiology/American Heart Association Task Force on Practice Guidelines and the Obesity Society. Obesity (Silver Spring) 2014;22(suppl 2):S5-S39.

5. Coen PM, Goodpaster BH. A role for exercise after bariatric surgery? Diabetes Obes Metab 2016;18:16-23.

6. Castello V, Simoes R, Bassi D, Catai A, Arena R, Borghi-Silva A. Impact of aerobic exercise training on heart rate variability and functional capacity in obese women after gastric bypass surgery. Obes Surg 2011;21:1739-1749.

7. Coen PM, Tanner CJ, Helbling NL, et al. Clinical trial demonstrates exercise following bariatric surgery improves insulin sensitivity. J Clin Invest 2015; $125: 248-257$.

8. Daniels P, Burns RD, Brusseau TA, et al. Effect of a randomised 12-week resistance training programme on muscular strength, cross-sectional area and muscle quality in women having undergone Roux-en-Y gastric bypass. J Sports Sci 2018;36:529-535.

9. Hassannejad A, Khalaj A, Mansournia MA, Rajabian Tabesh M, Alizadeh Z. The effect of aerobic or aerobic-strength exercise on body composition and functional capacity in patients with BMI $>/=35$ after bariatric surgery: a randomized control trial. Obes Surg 2017;27:2792-2801.

10. Deschenes MR, Kraemer WJ. Performance and physiologic adaptations to resistance training. Am J Phys Med Rehabil 2002;81:S3-S16.

11. Cooper R, Kuh D, Hardy R. Mortality Review Group on behalf of the FALCon and HALCyon study teams. Objectively measured physical capability levels and mortality: systematic review and meta-analysis. BMJ 2010;341:c4467. doi:10.1136/bmj. c4467

12. Physical Activity Guidelines Advisory Committee. 2018 Physical Activity Guidelines Advisory Committee Scientific Report. Washington, DC: US Department of Health and Human Services; 2018.
13. Lawman HG, Troiano RP, Perna FM, Wang CY, Fryar CD, Ogden CL. Associations of relative handgrip strength and cardiovascular disease biomarkers in U.S. adults, 2011-2012. Am J Prev Med 2016;50:677-683.

14. Ciangura C, Bouillot JL, Lloret-Linares C, et al. Dynamics of change in total and regional body composition after gastric bypass in obese patients. Obesity (Silver Spring) 2010;18:760-765

15. Chaston TB, Dixon JB, O'Brien PE. Changes in fat-free mass during significant weight loss: a systematic review. Int J Obes (Lond) 2007;31:743-750.

16. Herring LY, Stevinson C, Davies MJ, et al. Changes in physical activity behaviour and physical function after bariatric surgery: a systematic review and meta-analysis. Obes Rev 2016;17:250-261.

17. Verreijen AM, Verlaan S, Engberink MF, Swinkels S, de Vogel-van den Bosch J, Weijs PJ. A high whey protein-, leucine-, and vitamin D-enriched supplement preserves muscle mass during intentional weight loss in obese older adults: a double-blind randomized controlled trial. Am J Clin Nutr 2015;101:279-286.

18. Aron-Wisnewsky J, Verger EO, Bounaix C, et al. Nutritional and protein deficiencies in the short term following both gastric bypass and gastric banding. PLoS One 2016;11:e0149588. doi:10.1371/journal.pone.0149588

19. Hector AJ, Marcotte GR, Churchward-Venne TA, et al. Whey protein supplementation preserves postprandial myofibrillar protein synthesis during short-term energy restriction in overweight and obese adults. J Nutr 2015;145:246-252.

20. Miller PE, Alexander DD, Perez V. Effects of whey protein and resistance exercise on body composition: a meta-analysis of randomized controlled trials. J Am Coll Nutr 2014;33:163-175.

21. Fried M, Hainer V, Basdevant A, et al. Inter-disciplinary European guidelines on surgery of severe obesity. Int J Obes (Lond) 2007;31:569-577.

22. National Institute for Health. Gastrointestinal surgery for severe obesity: National Institutes of Health Consensus Development Conference Statement. Am J Clin Nutr 1992;55:615S-619S

23. Dunstan DW, Vulikh E, Owen N, Jolley D, Shaw J, Zimmet P. Community center-based resistance training for the maintenance of glycemic control in adults with type 2 diabetes. Diabetes Care 2006;29:2586-2591.

24. Colberg SR, Sigal RJ, Yardley JE, et al. Physical activity/exercise and diabetes: a position statement of the American Diabetes Association. Diabetes Care 2016;39:2065-2079.

25. Rothney MP, Brychta RJ, Schaefer EV, Chen KY, Skarulis MC. Body composition measured by dual-energy $\mathrm{x}$-ray absorptiometry half-body scans in obese adults. Obesity (Silver Spring) 2009;17:1281-1286.

26. Roberts HC, Denison HJ, Martin HJ, et al. A review of the measurement of grip strength in clinical and epidemiological studies: towards a standardised approach. Age Ageing 2011;40:423-429.

27. Daly RM, Miller EG, Dunstan DW, et al. The effects of progressive resistance training combined with a whey-protein drink and vitamin D supplementation on glycaemic control, body composition and cardiometabolic risk factors in older adults with type 2 diabetes: study protocol for a randomized controlled trial. Trials 2014;15:431. doi:10.1186/1745-6215-15-431

28. Comstock BA, Solomon-Hill G, Flanagan SD, et al. Validity of the Myotest(R) in measuring force and power production in the squat and bench press. J Strength Cond Res 2011;25:2293-2297.

29. Caruso JF, Olson NM, Taylor ST, et al. Front squat data reproducibility collected with a triple-axis accelerometer. J Strength Cond Res 2012;26:40-46.

30. Jidovtseff B, Harris NK, Crielaard JM, Cronin JB. Using the load-velocity relation ship for 1RM prediction. J Strength Cond Res 2011:25:267-270.

31. Dao HH, Frelut ML, Peres G, Bourgeois P, Navarro J. Effects of a multidisciplinary weight loss intervention on anaerobic and aerobic aptitudes in severely obese adolescents. Int J Obes Relat Metab Disord 2004;28:870-878.

32. Unick JL, Bond DS, Jakicic JM, et al. Comparison of two objective monitors for assessing physical activity and sedentary behaviors in bariatric surgery patients. Obes Surg 2012;22:347-352.

33. Tudor-Locke C, Brashear MM, Johnson WD, Katzmarzyk PT. Accelerometer profiles of physical activity and inactivity in normal weight, overweight, and obese U.S. men and women. Int J Behav Nutr Phys Act 2010;7:60. doi:10.1186/1479-5868-7-60

34. Freedson PS, Melanson E, Sirard J. Calibration of the Computer Science and Applications, Inc. accelerometer. Med Sci Sports Exerc 1998;30:777-781.

35. Leplege A, Ecosse E, Verdier A, Perneger TV. The French SF-36 Health Survey: translation, cultural adaptation and preliminary psychometric evaluation. J Clin Epidemiol 1998;51:1013-1023.

36. Oppert JM, Lahlou N, Laferrere B, Roger M, Basdevant A, Guy-Grand B. Plasma leptin and acute serotoninergic stimulation of the corticotropic axis in women who are normal weight or obese. Obes Res 1997;5:410-416.

37. Gesquiere I, Aron-Wisnewsky J, Foulon V, et al. Medication cost is significantly reduced after Roux-en-Y gastric bypass in obese patients. Obes Surg 2014;24:1896-1903.

38. Layman DK, Evans E, Baum JI, Seyler J, Erickson DJ, Boileau RA. Dietary protein and exercise have additive effects on body composition during weight loss in adult women. J Nutr 2005;135:1903-1910.

39. Seres L, Lopez-Ayerbe J, Coll R, et al. Increased exercise capacity after surgically induced weight loss in morbid obesity. Obesity (Silver Spring) 2006;14:273-279.

40. Jacobi D, Ciangura C, Couet C, Oppert JM. Physical activity and weight loss following bariatric surgery. Obes Rev 2011;12:366-377

41. Baillot A, Baillargeon JP, Brown C, Langlois MF. The 6-min walk test reflects functional capacity in primary care and obese patients. Int J Sports Med 2015;36:503-509. 
42. Hakkinen K, Kallinen M, Izquierdo M, et al. Changes in agonist-antagonist EMG, muscle CSA, and force during strength training in middle-aged and older people. $J$ Appl Physiol 1998;84:1341-1349.

43. Josse AR, Atkinson SA, Tarnopolsky MA, Phillips SM. Increased consumption of dairy foods and protein during diet- and exercise-induced weight loss promotes fat mass loss and lean mass gain in overweight and obese premenopausal women. J Nutr 2011;141:1626-1634.
44. Shah M, Snell PG, Rao S, et al. High-volume exercise program in obese bariatric surgery patients: a randomized, controlled trial. Obesity (Silver Spring) 2011;19:1826-1834.

45. Morton RW, Murphy KT, McKellar SR, et al. A systematic review, meta-analysis and meta-regression of the effect of protein supplementation on resistance training-induced gains in muscle mass and strength in healthy adults. Br J Sports Med 2018;52:376-384 